L'HOMME L'Homme

Revue française d'anthropologie

173 | 2005

Varia

\title{
Manga Bekombo Priso (1932-2004)
}

Alfred Adler

\section{OpenEdition}

Journals

Édition électronique

URL : http://journals.openedition.org/lhomme/25013

DOI : 10.4000/lhomme.25013

ISSN : 1953-8103

Éditeur

Éditions de l'EHESS

Édition imprimée

Date de publication : 1 mars 2005

Pagination : 7-10

ISSN : 0439-4216

\section{Référence électronique}

Alfred Adler, « Manga Bekombo Priso (1932-2004) », L'Homme [En ligne], 173| 2005, mis en ligne le 01 janvier 2007, consulté le 14 septembre 2020. URL : http://journals.openedition.org/lhomme/25013

(c) École des hautes études en sciences sociales 


\title{
Manga Bekombo Priso (1932-2004)
}

Alfred Adler

\begin{abstract}
$A_{u}$
U MOMENT DE LUI DIRE ADIEU, je ne peux m'empêcher de penser à des scènes funéraires auxquelles j'ai assisté, au sud du Tchad comme au NordCameroun. Les parents d'abord, mais aussi les amis proches, rassemblés autour du défunt, expriment à son adresse des récriminations, ils élèvent des protestations : qu'avons-nous fait, que t'avons-nous fait pour que tu nous quittes ainsi ? Pour que tu nous abandonnes? Ne sais-tu pas que nous avons besoin de toi? Qu'allons-nous devenir maintenant?

J'aurais moi aussi à lui faire de tels reproches, je voudrais aussi lui faire entendre mes plaintes d'être laissé sur le chemin, d'être comme abandonné après une si longue route parcourue ensemble.

Ma rencontre avec lui - elle remonte à bientôt 45 ans - a coïncidé avec les tout débuts de ma vie professionnelle comme chercheur (ou plutôt apprenti chercheur) africaniste. Georges Balandier m'avait recruté pour participer à une recherche sur les représentations et les attitudes liées au temps - son organisation conceptuelle et sa gestion pratique - dans les sociétés d'Afrique noire. La première chose qu'il fit alors, fut de me mettre en contact avec, me disait-il, l'un de ses meilleurs chercheurs africains, et c'était Manga Bekombo. À partir de ce moment, nous allions travailler en étroite collaboration pendant deux ans, mais je dois dire surtout que Manga allait tout simplement contribuer de la manière la plus efficace à me former, à me familiariser avec une Afrique dont je ne savais à peu près rien.

Ma formation s'est faite relativement vite et de façon agréable parce que tout de suite se sont noués entre Manga et moi des rapports d'amitié qui n'ont fait que s'approfondir au fil des années. Contraint d'avancer à marche forcée dans la connaissance livresque des sociétés et des cultures africaines, je dois à Manga d'avoir eu, grâce à lui, à travers lui, un contact vivant avec l'Afrique, une Afrique alors bouillonnante de son renouveau, une Afrique encore pleine d'espoir pour son avenir puisque nous étions tout juste au lendemain des indépendances.
\end{abstract}


Manga Bekombo était venu très jeune en France, il avait reçu une formation très complète dans les écoles et les universités françaises. C'était un intellectuel qui avait parfaitement assimilé les enseignements et la culture qui y étaient dispensés - d'abord comme psychologue, puis comme sociologue et enfin comme anthropologue tourné vers l'étude de sa société et de sa culture d'origine, celles des Dwala. Je dois dire que, comme intellectuel, et c'est ce que j'admirais et aimais en lui, il avait quelque chose de plutôt rare à l'époque : la culture qu'il avait acquise ne lui servait pas à prendre de la distance (avec ce que cela peut impliquer de hauteur) pour juger les cultures africaines et la sienne, en particulier. Elle lui a plutôt permis de développer un esprit critique très acéré vis-à-vis d'elle-même, et de la culture occidentale en général. Il n’a jamais été dupe de sa prétention à l'universalité. Mais, en même temps, tout en y étant viscéralement attaché, il a su exercer cet esprit critique vis-à-vis de l'Afrique, à l'endroit des États tout neufs sortis du carcan colonial, ainsi que dans ses recherches sur la culture et l'organisation sociale des Dwala auxquelles il a consacré sa vie professionnelle.

J'ai gardé un vif souvenir de nos discussions passionnées d'alors où j'apprenais tellement et pas seulement sur le Cameroun. Pas plus qu'il n’a idéalisé un Occident - qu'il n'exécrait pas (toute sa vie le prouve) -, il n'a idéalisé l'Afrique, celle du passé ou celle qui venait, en principe, de recouvrer sa liberté. Je peux témoigner qu'il n'avait pas attendu que paraisse un certain brûlot au titre ravageur, pour dire, avec le sourire malicieux qui était le sien, celui d'un sceptique et d'un sage, que décidément les choses partaient assez mal sur le continent noir.

Je dois à Manga de m'avoir quelque peu affranchi sur les problèmes politiques (je n'avais là-dessus pour tout bagage que ce que j'entendais dans les manifestations anticolonialistes d'étudiants - les manifs rituelles du 21 février) et, notamment, sur ce qui s'était passé dans le Sud du Cameroun - la répression impitoyable menée contre les dirigeants et les militants de l'UPC, le meurtre par les Français de Félix Moumié et les conditions dans lesquelles Ahidjo fut installé au pouvoir.

Le travail en commun sur le temps s'acheva et enfin, j'eus mon baptême du terrain. Je partis faire quelques mois d'enquête dans divers pays d'Afrique, en commençant par le Nigéria; je devais rester trois mois à Ibadan, au cœur de la civilisation yoruba. Je me souviendrais toujours de l'attitude si généreuse de Manga. J'appréhendais ce premier grand voyage; Manga le sentait et me conduisit dans sa voiture à Orly, où, durant la longue attente avant d'embarquer, il calma mes anxiétés et mon excitation et me parla comme un grand frère de ce que j'allais découvrir. Il prévint même son père pour le cas où j'irais à Douala. Le hasard de la météo voulut que mon avion ne puisse atterrir à Lagos et soit dérouté sur Douala où j'eus la joie de rencontrer et de passer quelques moments avec cet homme absolument remarquable qu'était le père de Manga, Dika Bekombo. Dika, nom que le destin permit à Manga de transmettre à son petit-fils peu avant de nous quitter. 
Dans les années qui suivirent, je voyais très régulièrement Manga dans l'un de ses lieux de travail, les sous-sols du Musée de l'Homme où il côtoyait Éric de Dampierre et aussi Michel Leiris; avec l'un comme avec l'autre, il entretenait des rapports amicaux et tous deux avaient pour lui la plus grande estime tant sur le plan intellectuel que sur celui de sa sensibilité car ils appréciaient beaucoup la sûreté et la finesse de son goût dans le domaine des arts africains. Survient encore un tournant de ma vie professionnelle auquel Manga est étroitement associé : c'est par lui que j'ai alors noué des liens avec Éric de Dampierre, et de cette amitié naquit notre commun désir de l'accompagner dans cette aventure que fut la création, dans le tumulte encore non apaisé des journées de fin mai 68 , du Laboratoire d'ethnologie et de sociologie comparative de Nanterre.

Je ne parlerai pas de l'activité considérable déployée par Manga au service du Laboratoire, de son infatiguable dévouement au quotidien, notamment pendant la période qui fut celle de la direction de notre amie Annie Lebeuf. Il y aurait trop à dire. Mais je ne peux pas ne pas rappeler son côté chaleureux, accueillant à tous : ce n'est pas par hasard si les réunions festives les plus conviviales eurent lieu chez lui, et si, par ailleurs, maints étudiants - qui ont fait du chemin depuis -, ont trouvé chez lui, dans sa maison, comme un nid où leur maturation d'ethnologues africanistes a pu s'accomplir dans un climat de confiance réciproque.

Je voudrais maintenant évoquer l'essentiel, le chercheur qu'il a été. Modeste, excessivement modeste, il n'a pas réuni dans des livres - lui qui a poursuivi si magnifiquement au service des autres sa collaboration à la collection des "Classiques africains » et le travail de publication réalisé par la Société d'ethnologie - ses innombrables articles, ses contributions à des ouvrages collectifs qui ont marqué notre discipline. Il n'a pas publié sa thèse sur l'organisation sociale des Dwala qui, à mes yeux, constitue un apport décisif à la connaissance des systèmes de parenté et de mariage africains. Il détestait le jargon qui permet de donner plus d'apparence scientifique à ce qui n'est parfois qu'un placage sur des descriptions plutôt superficielles. Il écrivait dans un langage simple et précis, et jamais autant qu'en le lisant - ou en écoutant ses exposés dans nos séminaires je n'ai eu le sentiment d'être mis en présence de la véritable complexité des structures sociales et de l'épaisseur d'un réel qu'on ne peut restituer pleinement que du dedans. Je ne citerai pour mémoire que l'exemple du muebe, terme par lequel on désigne au sein de l'unité domestique élargie - vaste ensemble résidentiel en principe patri-virilocal - les foyers matrifocaux créés par des femmes qui regroupent autour d'elles des coépouses et des enfants. Manga nous dit que ces foyers sont des lieux dont le mari est exclu et sur lesquels règnent, en couple dominant, la fondatrice et l'aîné ou le plus capable de ses fils. La réflexion approfondie à laquelle il s'est livré à ce sujet conduit à mettre en cause bien des idées qui ont cours dans nos milieux sur la filiation, sur les rapports entre hommes et femmes et sur l'alliance, de façon générale. Il faudrait aussi parler de la très belle édition qu'il a donnée aux "Classiques africains " de l'épopée dwala La Fantastique Histoire de Djeki-là-Njambé. Le texte du récit épique est précédé d'un avantpropos relativement bref mais extraordinairement dense. Dans sa manière habi- 
tuelle, avec un langage simple et profond, Manga nous dit l'essentiel sur cette figure de héros culturel en lequel se résume l'ensemble de l'univers social et spirituel des Dwala et aussi des populations voisines qui partagent leurs conceptions du monde.

Manga termine son avant-propos en faisant l'éloge - un éloge que je crois pouvoir lui adresser à lui-même - de l'artiste avec lequel il avait travaillé, le musiciennarrateur, Diboko Kollo. Il écrit : «Avec une éloquence sobre et dans un style où l'imagination, bien que débordante, n'est jamais ternie par l'extravagance, [il] a su nous présenter un Jeki conçu dans toute sa plénitude, c'est-à-dire, en dernière analyse, l'homme, avec ses aspirations les plus anciennes, habité des désirs les plus forts ». Ses derniers mots sont pour dire: "En somme, l'histoire de Jeki-làNjambé Inono est le récit de ce combat de l'esprit pour la vie, tel qu'il se déroula dans le mythe, tel qu'il se poursuit dans le rêve d'aujourd'hui et se continuera encore avec le renouvellement des générations ». C'est avec ces mots-là, ses mots à lui, aussi profondément dwala qu'universels, que je veux lui dire adieu. Adieu Manga, mon ami, mon frère. 